OPEN ACCESS

Edited by: Kelen Cristina Ribeiro Malmegrim,

University of São Paulo, Brazil

Reviewed by:

Philippe Saas,

INSERM UMR1098 Interactions Hôte-Greffon-Tumeur \& Ingénierie

Cellulaire et Génique, France Federica Casiraghi, Istituto Di Ricerche Farmacologiche Mario Negri, Italy

*Correspondence: Kristofor K. Ellestad ellestad@ualberta.ca;

Colin C. Anderson colinand@ualberta.ca

Specialty section: This article was submitted to Alloimmunity and Transplantation,

a section of the journal

Frontiers in Immunology

Received: 21 October 2017 Accepted: 04 January 2018

Published: 24 January 2018

Citation: Ellestad KK, Thangavelu G, Haile Y,

Lin J, Boon L and Anderson CC (2018) Prior to Peripheral Tolerance,

Newly Generated CD4 T Cells Maintain Dangerous Autoimmune

Potential: Fas- and Perforin-

Independent Autoimmunity Controlled by Programmed Death-1.

Front. Immunol. 9:12.

doi: 10.3389/fimmu.2018.00012

\section{Prior to Peripheral Tolerance, Newly Generated CD4 T Cells Maintain Dangerous Autoimmune Potential: Fas- and Perforin-Independent Autoimmunity Controlled by Programmed Death-1}

\author{
Kristofor K. Ellestad ${ }^{1,2 *}$, Govindarajan Thangavelu ${ }^{2,3}$, Yohannes Haile ${ }^{2}$, Jiaxin Lin ${ }^{2,3,4}$, \\ Louis Boon ${ }^{5}$ and Colin C. Anderson ${ }^{1,2,3,4 *}$
}

${ }^{1}$ Department of Medical Microbiology and Immunology, University of Alberta, Edmonton, AB, Canada, ${ }^{2}$ Alberta Diabetes Institute, University of Alberta, Edmonton, $A B$, Canada, ${ }^{3}$ Department of Surgery, University of Alberta, Edmonton, $A B$, Canada, ${ }^{4}$ Alberta Transplant Institute, University of Alberta, Edmonton, AB, Canada, ${ }^{5}$ Bioceros B.V., Utrecht, Netherlands

Lymphopenia can result from various factors, including viral infections, clinical interventions, or as a normal property of the fetal/neonatal period. T cells in a lymphopenic environment undergo lymphopenia-induced proliferation (LIP) to fill the available "niche" as defined by peptide-MHC and homeostatic cytokine resources. We recently reported systemic autoimmunity following reconstitution of the lymphoid compartment of Rag $1^{-/-}$mice with PD-1/- hematopoietic stem cells or by transfer of thymocytes, but not splenocytes, suggesting that programmed death-1 (PD-1) plays a crucial role in controlling recent thymic emigrants (RTE) and preventing autoimmunity upon their LIP. However, it is unclear whether RTE residing within the periphery of a lymphoreplete host maintain enhanced autoimmune generating potential or if this property only manifests if RTE experience a lymphopenic periphery immediately after export from the thymus. Furthermore, it is unclear which of a variety of $T$ cell effector mechanisms generate pathology when control of RTE by PD-1 is lacking. Herein, we determined that PD-1 is upregulated on CD4 T cells undergoing the natural LIP characteristic of the neonatal period. Newly generated T cells lacking PD-1 maintained an enhanced autoimmune potential even after residence in a lymphoreplete periphery, emphasizing the importance of PD-1 in the establishment of peripheral tolerance. Neither Fas nor perforin-dependent killing mechanisms were required for autoimmunity, while host MHC-II expression was critical, suggesting that LIP-driven autoimmunity in the absence of PD-1 may primarily result from a CD4 T cell-mediated systemic cytokinemia, a feature potentially shared by other autoimmune or inflammatory syndromes associated with immune reconstitution and LIP.

Keywords: tolerance, autoimmunity, co-stimulation, co-inhibition, lymphopenia, checkpoint inhibitor, cytokine storm, graft versus host

Abbreviations: LIP, lymphopenia-induced homeostatic proliferation; HSC, hematopoietic stem cells; pTreg, peripherally generated regulatory T cell; Treg, regulatory T cell; SP, single positive; RTE, recent thymic emigrants; pMHC, peptide-MHC; Tcon, conventional T cell; PD-1, programmed death-1; MFI, mean fluorescence intensity; WT, wild type. 


\section{INTRODUCTION}

Thymic selection processes can be viewed as the first "filtration" step on the developing $\mathrm{T}$ cell repertoire. Although these processes serve to remove the majority of strongly self-reactive $\mathrm{T}$ cells from the developing repertoire or convert them to thymic Treg, some self-reactive conventional $\mathrm{T}$ cell (Tcon) clones escape (1). This is, for example, evidenced by the ability to induce autoimmune diseases, such as myelin-oligodendrocyte glycoprotein-induced experimental autoimmune encephalomyelitis in mice (2). Peripheral tolerance mechanisms, such as tuning, anergy, deletion, or conversion to peripherally generated Treg ( $\mathrm{p}$ Treg), are thus important for the establishment and maintenance of immune tolerance and can be viewed as a second filter on the peripheral $\mathrm{T}$ cell repertoire.

Aside from the naturally lymphopenic neonatal period associated with immune system development (3), lymphopenia also occurs in a variety of clinical settings. Hematopoietic cell transplantation, $\mathrm{T}$ cell depleting therapy for solid organ transplantation, cancer chemotherapy, as well as HIV infection are all associated with lymphopenia of varying severity. In the lymphopenic state, cells undergo a process known as lymphopeniainduced proliferation (LIP), which is facilitated and regulated in its extent by the availability of "resources" for T cells that together define T cell "space" (4). These include peptide-MHC complexes (derived from self or otherwise) that can mediate at least a weak, "tonic" signal through the TCR, as well as homeostatic cytokines, such as IL-7 and IL-15. Regulatory T cells (Treg) (5-13), costimulatory molecules such as $\operatorname{CD} 28(7,14)$, as well as molecules with known co-inhibitory activity [e.g., BTLA (15), LAG-3 (16), TGFBRII $(17,18)]$ can modulate the kinetics of LIP and the maximum size of the $\mathrm{T}$ cell compartment. In addition, LIP can promote autoimmune disease and LIP of TGFßRII ${ }^{-/} \mathrm{T}$ cells results in autoimmunity (17).

Programmed death-1 (PD-1), a co-inhibitory receptor expressed on activated $\mathrm{T}$ cells, enters the immune synapse upon $\mathrm{T}$ cell:APC interaction and is known to recruit the phosphatase SHP2 upon receptor ligation which can dampen proximal TCR signaling cascades $(19-21)$ or co-stimulatory signals through $\mathrm{CD} 28$ (22). In contrast to the $\mathrm{C} 57 \mathrm{BL} / 6 \mathrm{PD}-1^{-/-}$mouse, which displays a relatively mild phenotype characterized by development of a lupus-like disease with spontaneous arthritis and glomerulonephritis upon aging (23), we have shown that reconstitution of the lymphoid compartment of lymphopenic adult $\operatorname{Rag} 1^{-/-}$animals via transfer of PD-1 $1^{-/-}$hematopoietic stem cells (HSC) leads to a rapid, severe, and lethal systemic autoimmune disease soon after the first newly generated $\mathrm{T}$ cells, or recent thymic emigrants (RTE), emerge into the periphery (24). The disease is associated with infiltration of CD4 and CD8 T cells into multiple organs, including heart, liver, and kidney, although $\operatorname{Rag}^{-/-} \mathrm{K}^{\mathrm{b}-/-} \mathrm{D}^{\mathrm{b}-/-}$ animals remain fully susceptible suggesting that MHC-I-restricted CD8 T cells are dispensable for disease. Significantly elevated levels of several pro-inflammatory cytokines and chemokines in serum (24) as well as elevated pro-inflammatory cytokine transcripts in infiltrated organs (25) are also associated with disease. Macroscopically the disease is characterized by kyphosis, cachexia, diarrhea, and skin and ocular lesions. Interestingly,
PD-1 ${ }^{-/-}$HSC reconstitution of day $1 \mathrm{Rag}^{-/-}$neonates results in a drastically reduced incidence of disease (24), suggesting that limited T cell "space" due to small anatomic size (e.g., of lymph nodes) or other factors can limit the aberrant activation of $\mathrm{T}$ cells promoted by LIP. Indeed lymph node-deficient $\mathrm{Rag}^{-/} \gamma \mathrm{c}^{-/-}$or irradiated $\mathrm{LTo}^{-/-}$hosts were also resistant to disease after $\mathrm{PD}-1^{-/-}$ HSC transfer (24). Transfer of PD-1-deficient thymocytes to adult Rag $1^{-/-}$mice likewise results in autoimmunity; however, transfer of splenocytes from mature $\mathrm{PD}-1^{-/}$mice does not result in disease. These data suggest that the RTE/newly generated $\mathrm{T}$ cell population, which has not yet been subject to peripheral tolerance mechanisms, has greater autoimmune potential than established peripheral T cells and that PD-1 is critically important for controlling their activity during LIP. However, several lines of evidence suggest that newly generated $\mathrm{T}$ cells have properties that promote tolerance (26). It is not clear whether newly generated $\mathrm{T}$ cells in an adult retain a heightened potential for the generation of autoimmunity after their emergence into the periphery or whether exposure of newly generated $\mathrm{T}$ cells to a lymphoreplete environment leads to their rapid tolerization. Herein, we have taken advantage of the Rag2pGFP transgenic (Tg) mouse strain in which GFP is expressed during early $\mathrm{T}$ cell development and remains detectable as a marker of newly generated lymphocytes after their emergence into the periphery $(27,28)$. $\mathrm{PD}-1^{-/}$peripheral newly generated $\mathrm{T}$ cells or established $\mathrm{T}$ cells were purified from adult mice and tested for their ability to drive autoimmunity upon transfer into lymphopenic hosts. We found that purified peripheral PD-1 $1^{-/}$newly generated $\mathrm{T}$ cells are similar to thymocytes in their ability to drive systemic autoimmunity upon transfer to lymphopenic hosts. Using lymphopenic hosts lacking Fas or MHC-II expression, or PD-1 ${ }^{-/-}$donors lacking perforin expression, we also show that host MHC-II expression is required for disease after PD- $1^{-l-}$ HSC transfer, and that Fas- and perforindependent killing mechanisms are dispensable for disease. Taken together, our data suggest that even in a lymphoreplete adult host, peripheral newly generated $\mathrm{T}$ cells retain a heightened potential for LIP-driven autoimmunity in the absence of PD-1, which is mediated by CD4 $\mathrm{T}$ cells.

\section{MATERIALS AND METHODS}

\section{Mice}

B6.129S7-Rag1 ${ }^{\mathrm{tm} 1 \mathrm{Mom} / \mathrm{J}}\left(\mathrm{Rag}^{-/-}, \mathrm{Rag}^{-/-}\right)$, B6.Cg-Foxp3 $3^{\mathrm{tm} 2 \text { (EGFP)Tch} / J}$ (FoxP3 ${ }^{\mathrm{EGFP}}$, used in the present manuscript as WT), B6.MRL$\mathrm{Fas}^{\mathrm{lpr}} / \mathrm{J}\left(\mathrm{Fas}^{\mathrm{lpr}}\right), \mathrm{C} 57 \mathrm{BL} / 6-\mathrm{Prf1}^{\mathrm{tm} 1 \mathrm{Sd} z} / \mathrm{J}\left(\mathrm{Prf1}^{-/-}\right)$, and B6.129S2Ciita $^{\mathrm{tm} 1 \mathrm{Ccum}} / \mathrm{J}\left(\mathrm{CiiTA}^{-/-}\right)$mice were purchased from The Jackson Laboratory (Bar Harbor, ME, USA). Days 13-14 gestation pregnant C57BL/6-CD45.1 (B6-CD45.1) mice were purchased from NCI (Frederick, MD, USA). C57BL/6-Pdcd1 $1^{-/}$(backcrossed 11 generations to $\mathrm{C} 57 \mathrm{BL} / 6)$ were originally generated by Prof. T. Honjo and colleagues (23). FoxP3 ${ }^{\mathrm{EGFP}} \times P d c d 1^{-/-}$mice were generated by crossing the above FoxP3 ${ }^{\mathrm{EGFP}}$ and $\mathrm{B} 6-\mathrm{Pdcd1^{-1- }}$ mice and are referred to in the present manuscript simply as $\mathrm{PD}-1^{-/}$. PD $-1^{-/-} \times \mathrm{Prf1}^{-/-}$mice were generated by crossing the above $\mathrm{PD}-1^{-/-}$and $\mathrm{Prf1}^{-/-}$mice without any selection for the FoxP3 ${ }^{\text {EGFP }}$ transgene. $\mathrm{Rag}^{-/-} \times \mathrm{CiiTA}^{-/-}$mice were generated by 
crossing the above $\mathrm{Rag}^{-/-}$and CiiTA ${ }^{-/-}$mice. Fas ${ }^{\mathrm{lpr}} \times \mathrm{Rag}^{-/-}$mice were generated by crossing the above $\mathrm{Fas}^{\mathrm{lpr}}$ and $\mathrm{Rag}^{-/-}$mice. B6.Rag2pGFP (Rag2pGFP) mice $(27,28)$ were kindly provided by Pamela Fink (University of Washington, Seattle, WA, USA). Rag2pGFP $\times \mathrm{PD}^{-1^{-/}}$mice were generated by crossing Rag2pGFP mice with the above B6-Pdcd1 $1^{--}$, with screening and selection of breeders for high GFP expression. Marilyn Rag2 ${ }^{-/-} \mathrm{CD}^{+}$antiHY/I-A ${ }^{\text {b } T C R ~ T g ~ m i c e ~(c a l l e d ~ M a r i l y n ~ h e r e i n) ~ w e r e ~ g e n e r a t e d ~ b y ~}$ Lantz and colleagues (29) and were originally obtained from the NIAID exchange program. Cells from Marilyn mice were tracked based on their expression of CD4, CD45.2, and a V $\beta 6$ TCR and lack of CD45.1. Animals were cared for in accordance with the guidelines of the Canadian Council on Animal Care and housed under clean conventional housing conditions at the University of Alberta Health Sciences and Laboratory Animal Services facilities (HSLAS).

\section{Cell Preparations and Adoptive Transfer Experiments}

For experiments involving transfer of thymocytes or peripheral $\mathrm{T}$ cells, recipient NK cells were depleted [to avoid potential NK-mediated killing of the input cells (30-32)] by treatment on days $-4,-1$, and +2 with $0.3 \mathrm{mg}$ per mouse of anti-NK1.1 (PK136) injected intraperitoneally. Thymocytes or splenocytes for injection were prepared by disruption in HBSS (Gibco) $+2 \%$ fetal bovine serum (FBS, Sigma-Aldrich) through a 70- $\mu$ m nylon cell strainer. Cells were centrifuged at $\sim 300 \times g$ for 5-10 min at room temperature, and red blood cell lysis was performed by resuspending cells in ACK lysis buffer $\left(150 \mathrm{mM} \mathrm{NH}_{4} \mathrm{Cl}\right.$, $10 \mathrm{mM} \mathrm{KHCO}, 0.1 \mathrm{mM} \mathrm{Na}_{2}$ EDTA) with incubation for $5 \mathrm{~min}$, followed by addition of $\sim 10$ volumes of HBSS $+2 \%$ FBS, and two cycles of centrifugation at $\sim 300 \times g$ for $5-10 \mathrm{~min}$, and resuspension in PBS with no additives. If cells were prepared for further manipulation (e.g., staining and sorting), they were instead washed and resuspended in HBSS $+2 \%$ FBS. For experiments involving adoptive transfer of HSC, fetal liver cells (FLC; embryonic days 14-15) were used as a source of HSC. On ice, fetal livers were disrupted by repeated trituration through a 5-mL serological pipet, followed by filtration through a 70- $\mu \mathrm{m}$ nylon mesh filter basket. Cells were then centrifuged at $\sim 300 \times g$ for $10 \mathrm{~min}$ at $4^{\circ} \mathrm{C}$, and resuspended according to their intended further use. FLC were used either fresh or frozen. For immediate use for in vivo transfers, FLC were resuspended at $50 \times 10^{6}$ cells $/ \mathrm{mL}$ in PBS. For freezing, cells were resuspended at $2 \times 10^{8}$ cells $/ \mathrm{mL}$ in $90 \%$ FBS $+10 \%$ DMSO, frozen in a $-1^{\circ} \mathrm{C}$ per minute rate-controlled cell freezing apparatus in a $-80^{\circ} \mathrm{C}$ freezer and transferred to the vapor phase of a liquid nitrogen tank for long-term storage. $1.5 \times 10^{7}$ fresh or frozen FLC were transferred intravenously to the indicated recipients. In islet transplantation experiments, female $\mathrm{Rag}^{-/}$recipients with an established islet transplant received a mixture of 4:1 female B6-CD45.1 and female Marilyn FLC (total of 10-15 $\times 10^{6}$ cells). Sex of fetuses was determined by PCR as described (33).

\section{Definition of Disease and Data Analysis}

Macroscopic signs of disease in HSC/thymocyte/peripheral cell recipients included cachexia/weight loss (>15\%), kyphosis (hunched appearance), ruffled fur, dermatitis, ocular lesions, and diarrhea. Recipient mice were no longer considered disease free when two or more of the above symptoms were evident, or if mice lost $\geq 20 \%$ body weight. For thymocyte experiments, calculation of weight loss for disease determination was performed relative to weights at day 0 or day 1 relative to cell transfer. For HSC experiments, calculation of weight loss was determined relative to initial weight measurements taken prior to day 30. Unless otherwise indicated, animals were used at $8-16$ weeks of age.

\section{Islet Transplantation}

Diabetes was induced in recipient mice via treatment with streptozotocin (Sigma-Aldrich) at $185-190 \mathrm{mg} / \mathrm{kg}$. Recipients were considered to be diabetic after two consecutive blood glucose measurements of $>20 \mathrm{mM}$ using a OneTouch Ultra glucometer (Lifescan Canada, Burnaby, BC, Canada). Pancreatic islets were isolated from male or female $\mathrm{Rag}^{-/-}$mice as previously described (34). Diabetic recipients were transplanted with 500 islets placed under the kidney capsule and thereafter monitored for return to normoglycemia. All recipients returned to normoglycemia within $48 \mathrm{~h}$ of islet transplantation and remained normoglycemic until they were given FLC between 3 and 6 months after islet transplantation; post fetal liver injection some mice with male islets became hyperglycemic (rejected the islet transplant) as described in the Section "Results."

\section{Antibodies, Flow Cytometry, and Fluorescence-Activated Cell Sorting (FACS)}

For flow cytometric staining and sorting, fluorophore-labeled antibodies against the following markers were obtained from eBioscience (San Diego, CA, USA) unless otherwise indicated: CD4 (RM4-5), TCR $\beta$ (H57-597), CD8a (53-6.7), PD-1 (J43), Ki-67 (SolA15), CD44 (IM7), CD19 (1D3), Granzyme B (NGZB), CD45.1 (A20), CD45.2 (104), Vß6 (RR4-7). Antibodies were used at manufacturer's recommended concentrations. Flow cytometric staining always used an Fc block cocktail to block nonspecific staining. Fc block cocktail consisted of $3 \mathrm{~mL}$ each of normal mouse, rat, and hamster serum, with addition of $0.3 \mathrm{mg}$ of anti-CD16/32 antibody (clone $2.4 \mathrm{~g} 2$, BioXCell). Fixation and permeabilization were performed using the eBioscience FoxP3 Fixation/Permeabilization buffer kit (Thermo Fisher) according to the manufacturer's protocols. For cell sorting, a BD Influx cell sorter was used controlled with Spigot software (Beckton Dickinson, Franklin Lakes, NJ, USA). Briefly, for sorting source cells were stained and resuspended in HBSS + 20\% FBS + 10 mM HEPES and sorted directly into FBS supplemented with $10 \mathrm{mM}$ HEPES. Standard flow cytometric analysis was performed using a BD LSR II instrument. Flow cytometric data analysis was performed using FlowJo (Treestar software, Portland, OR, USA).

\section{Statistical Analysis}

Statistical analysis was performed using Graphpad Prism software. Details of statistical tests used are provided in figure legends. 
However, in general, for comparisons of two groups, Student's $t$-test was used. In cases of comparison of groups with unequal variances, Welch's correction was applied. Unless otherwise noted, for multiple group comparisons, one-way ANOVA with Tukey's multiple comparison test was used. Disease onset/incidence was compared by the Kaplan-Meier method. Probability values reported for survival curve comparisons were calculated using the Mantel-Cox method.

\section{RESULTS}

\section{PD-1 Expression Is Tied to Lymphopenia- Induced Proliferation in Newly Generated T Cells}

Programmed death-1 expression appears to be critical for the generation of immune tolerance during LIP of newly generated $\mathrm{T}$ cells. We previously showed that newly generated $\mathrm{T}$ cells in a lymphopenic setting (i.e., in a lymphopenic recipient of WT HSC) had a high proportion of PD-1 expressing T cells that diminished over time (24). Whether the higher PD-1 expression on newly generated $\mathrm{T}$ cells was dependent on exposure to the lymphopenic environment or is an intrinsic property of newly generated $\mathrm{T}$ cells even in lymphoreplete mice has not been fully assessed. We, therefore, examined PD-1 expression in the steady state in both TCR $\beta^{+}$thymocytes and peripheral splenocytes from 10- to 12-week-old adult Rag2pGFP animals (Figures 1A,B). Unexpectedly, peripheral newly generated CD4 single positive (SP) splenocytes expressed very little PD-1 while approximately $15 \%$ of established or "mature" GFP- CD4 SP T cells were found to be PD-1 positive (Figure 1A). Likewise, mean fluorescence intensity of PD-1 staining was significantly higher in the CD4 SP $\mathrm{GFP}^{-}$cells compared to the $\mathrm{GFP}^{+}$ population (Figure 1B). Neither established nor newly generated T cells within the splenic CD8 SP population expressed appreciable levels of this co-inhibitor. Within the thymocyte population, approximately $90 \%$ of the CD4 SP and $85 \%$ of the CD8 SP were $\mathrm{GFP}^{+}$(data not shown), with the remainder presumably representing mature cells that had recirculated from the periphery back to the thymus, although it is conceivable that at least a subset could represent cells that failed to exit the thymus for longer than 3 weeks post-VDJ recombination (28). $\mathrm{GFP}^{+}$thymic CD4 and CD8 SP cells were slightly enriched for PD-1 positivity (3.1 and 2.6\% positive, respectively, Figure 1A) compared to their splenic counterparts (both 1.3\%), although this difference was not statistically significant. Similar to what was seen in splenocytes, the thymic CD4 SP GFP- population contained a sizeable population of $\mathrm{PD}-1^{+}$cells (26\%), and thus, these more established cells had higher overall PD-1 expression compared to the $\mathrm{GFP}^{+}$newly generated $\mathrm{T}$ cell population (Figures 1A,B). Unlike their splenic counterparts, there was a trend toward increased $\mathrm{PD}-1$ positivity and overall $\mathrm{PD}-1$ expression in the thymic CD8 SP GFP ${ }^{-}$cells compared to the $\mathrm{GFP}^{+}$cells although this difference was not statistically significant (Figures 1A,B).

Thus far, our data indicated that in the steady state, RTE of adult lymphoreplete mice do not express high levels of PD-1
(Figure 1) while adoptive transfer of RTE-generating HSC to lymphopenic mice did lead to high PD-1 expression (24). We, therefore, asked whether heightened PD-1 expression is peculiar to LIP in adoptive transfer or whether it might occur naturally (without adoptive transfer) during the LIP triggered by the lymphopenic state of the neonatal period (3). We examined PD-1 expression on peripheral lymphocytes of 10-day-old Rag2pGFP neonatal mice. More than $97 \%$ of thymic CD4 SP cells are $\mathrm{GFP}^{+}$in young Rag2pGFP mice (Figure S1B in Supplementary Material), and all splenic T cells in 10-day-old neonates would be considered to be newly generated based on elapsed time from initial development and, therefore, might also be expected to be $\mathrm{GFP}^{+}$. However, a significant percentage ( 30\% of CD4, $\sim 65 \%$ of CD8) of the splenic T cells had lost detectable GFP fluorescence in 10-day-old neonates (Figure 1C). The association between loss of GFP in CD4 T cells and acquisition of a CD44 ${ }^{\text {high }}$ memory phenotype, as well as an association of CD44 with Ki-67 expression, a marker of cycling cells (Figure 1D, upper panels) suggests that this was due to these cells having undergone multiple rounds of LIP, diluting GFP. Importantly, loss of GFP expression, high CD44 expression, and high Ki-67 expression were all associated with elevated PD-1 expression (Figure 1D, bottom panels): more than $90 \%$ of $\mathrm{PD}$-1-expressing CD4 T cells were Ki-67 high. Very few CD8 T cells expressed PD-1 in the neonates at this age and PD-1 expression was not associated with heightened $\mathrm{Ki}-67$ expression in these cells (Figure S1A in Supplementary Material).

Together, these data indicate that while PD- 1 is upregulated on T cells following LIP or a period of residency in the periphery (possibly due to encounter with antigen), only very low/barely detectable levels of PD-1 are expressed on newly generated adult T cells. Thus, the heightened PD-1 expression on newly generated $\mathrm{T}$ cells seen in lymphopenic HSC recipients is not an intrinsic characteristic of these cells but is LIP-induced. The naturally occurring LIP of the neonatal period also upregulated PD-1 on newly generated CD4 T cells, suggesting PD-1 is involved in establishing tolerance under physiologic conditions (i.e., not just under conditions of cell transfer).

\section{Steady State Peripheral Newly Generated T Cells in Adult Mice Maintain Heightened Autoimmune Potential Relative to Established T Cells}

Our previous studies showed that newly generated $\mathrm{T}$ cells exported from the thymus directly into a lymphopenic environment are critically dependent on PD-1 to establish tolerance and prevent autoimmunity. In contrast, PD-1 was not needed to maintain tolerance after transfer of peripheral $\mathrm{T}$ cells from PD- $1^{-/-}$adult animals, which would largely be comprised of established cells. However, it is unknown whether steady-state newly generated $\mathrm{T}$ cells in the periphery of immunocompetent adult mice retain this heightened potential for autoimmunity or if instead the peripheral tolerance process is rapid and newly generated $\mathrm{T}$ cells are immediately tolerized upon export to a lymphoreplete environment. In order to test the hypothesis that steady-state peripheral RTE/newly generated T cells had 
A
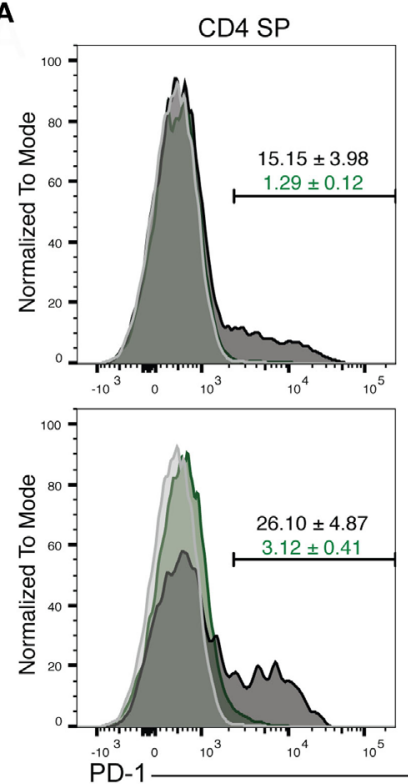

PD-1

B

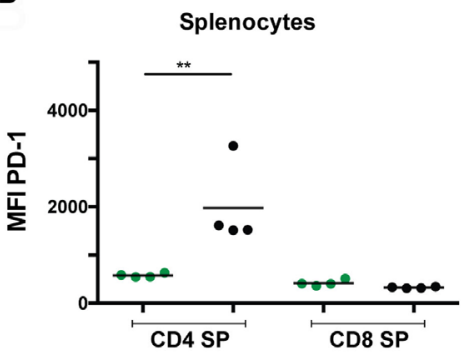

CD8 SP

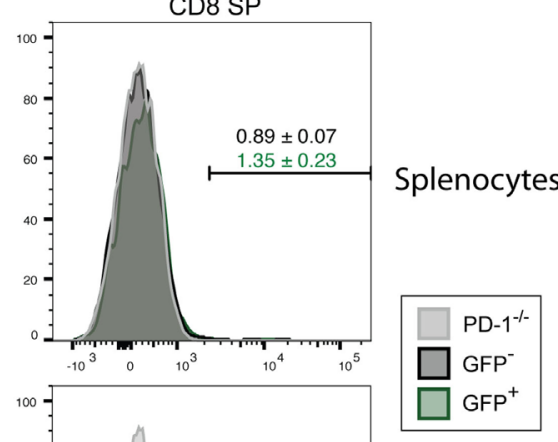

Thymocytes

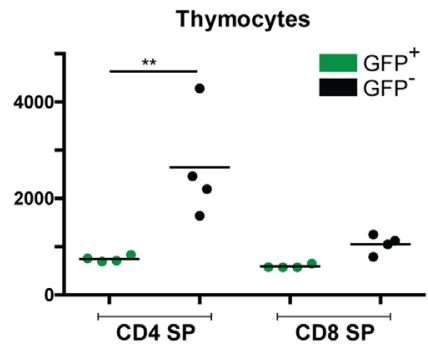

C

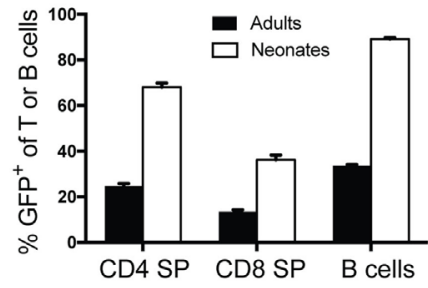

D
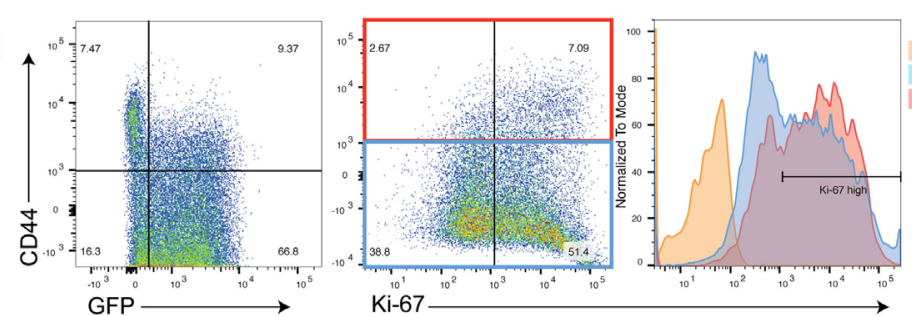

Isotype control

CD44 low (58\% Ki-67 high)

CD44 high (73\% Ki-67 high)
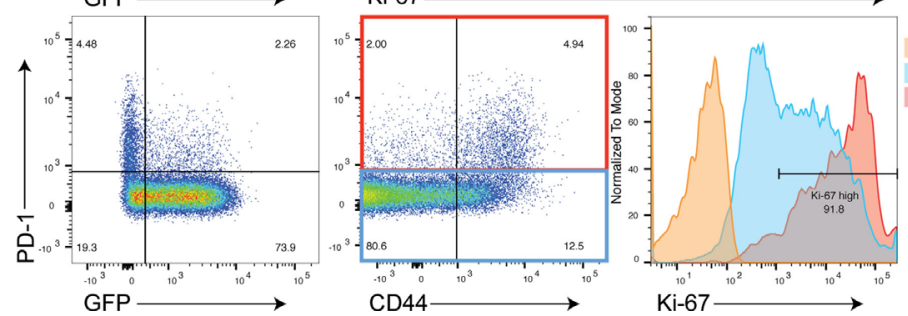

Isotype control

PD-1 $(57 \%$ Ki-67 high)

PD $-1^{+}$(92\% Ki-67 high)

FIGURE 1 | Newly generated T cells in adults lack programmed death-1 (PD-1) expression while in neonates their expression of PD-1 is linked to LIP. (A) Representative flow cytometric analysis of splenocytes and thymocytes from 10- to 12-week-old adult Rag2pGFP mice for PD-1 expression among TCR $\beta^{+}$CD4 or CD8 single positive (SP) cells that are GFP+ (newly generated T cells) or GFP- (mature cells). T cells from PD-1/- mice were also stained as a control for background. Values above gates are the group average \%PD-1 positive cells within the mature GFP- population (black text) or GFP+ population (green text), \pm SEM. (B) Mean fluorescence intensity (MFI) of PD-1 staining in CD4 or CD8 SP, GFP+ or GFP- T cells from Rag2pGFP splenocytes or thymocytes from the experiment depicted in (A). ${ }^{* \star} p<0.01$, one-way ANOVA with Tukey's multiple comparison test. (C) Comparison of percent GFP+ cells among peripheral splenocytes in the indicated cell populations in adult vs. neonatal mice \pm SEM. $n=8$ per group. (D) Representative $(n=3)$ flow cytometry plots of the indicated markers in splenic TCR $\beta^{+}$CD4 SP T cells from 10-day-old Rag2pGFP neonates. Histogram (right) analyses of Ki-67 on CD44 high or PD-1 high cells and CD44 low/negative cells or PD-1 low/negative cells employed gates as shown in the red and blue rectangles (middle dot plots), respectively. Data presented are from samples that were either permeabilized and stained with antibodies to TCR $\beta$, CD4, CD8, PD-1, CD44, and Ki-67, or non-permeabilized and stained with antibodies to TCR $\beta$, CD4, CD8, PD-1, and CD44 (to allow analysis of GFP). 
increased ability to drive autoimmunity in a lymphopenic host, we generated B6 Rag2pGFP x PD-1 $1^{-1-}$ mice and purified the $\mathrm{GFP}^{+}$or $\mathrm{GFP}^{-} \mathrm{T}$ cell populations from splenocytes of adult animals by FACS. Purified cells or thymocytes containing an equivalent number of SP T cells were transferred to $\mathrm{Rag}^{-/-}$ recipient animals and disease was monitored. Approximately 20 days after transfer, mice that received either PD-1 $1^{-/}$thymocytes or purified $\mathrm{GFP}^{+}$newly generated $\mathrm{T}$ cells began to develop autoimmune disease while the recipients of established cells were relatively spared (Figure $\mathbf{2 A}$, left panel). Similarly, while all recipient mice lost some weight beginning almost immediately after cell transfer until around 2 weeks posttransfer, after this point $\mathrm{PD}-1^{-/-}$established $\mathrm{T}$ cell recipients began to regain their lost weight while the thymocyte and newly generated $\mathrm{T}$ cell recipients clearly and significantly diverged from the established cell recipients and continued to lose weight (Figure 2A, right panel). Despite the clearly higher propensity of newly generated vs. established cells to drive autoimmunity, it should be mentioned that a low proportion of the $\mathrm{GFP}^{-}$established $\mathrm{T}$ cell recipients also met the criteria for disease albeit at a much later time point relative to the other groups (Figure 2A). Approximately, $40 \%$ of the purified $\mathrm{GFP}^{+}$ newly generated cells were CD4 SP and 56\% were CD8 SP (a CD4:CD8 ratio of $~ 0.7: 1$ ), whereas the purified GFP- population contained approximately $80 \%$ CD 4 SP and 17\% CD8 SP (CD4:CD8 ratio $\sim 4.7: 1$, Figure 2B). While our experiments were designed to test whether the newly generated $\mathrm{T}$ cells as a whole have heightened autoimmune potential, the differences in the proportions of CD4 vs. CD8 SP cells in newly generated vs. established T cells could potentially contribute to the differences in their ability to drive disease.

\section{T Cells with Specificity for a Neo-Self Antigen Can Persist in the Periphery with a Slow Decline in Frequency Over time}

The finding that newly generated $\mathrm{T}$ cells have a greater potential for autoimmunity than established peripheral $\mathrm{T}$ cells appears incongruent with several reported aspects of RTE biology (26) such as reduced effector functions or an increased propensity to convert to pTreg $(25,35,36)$ compared with established $\mathrm{T}$ cells. These studies raise the question of how newly generated $\mathrm{T}$ cells could have a greater capacity to cause autoimmune disease. There are at least two "filters" against self-reactivity, namely central and peripheral tolerance. We surmised that newly generated $\mathrm{T}$ cells may have a greater potential for generating autoimmunity because they have yet to pass through the second filter, peripheral tolerance. Autoimmunity caused by newly generated $\mathrm{T}$ cells during LIP might be due in part to a greater frequency of $\mathrm{T}$ cells with self-specific receptors than are present in the established $\mathrm{T}$ cells that have undergone peripheral tolerance mechanisms, such as deletion or conversion to pTreg. In order to explore the concept that potentially dangerous self-reactive cells could persist for a significant length of time in a lymphoreplete periphery post immune reconstitution of lymphopenic mice and be held in check by peripheral tolerance mechanisms without resulting in overt immune pathology, we used the HY antigen expressed by an established graft as a model neo-self antigen (33). We gave mixed Marilyn (anti-male antigen, HY/ $\mathrm{IA}^{\mathrm{b}}$ ) and WT B6 female HSC to $\mathrm{Rag}^{-/-}$female mice bearing an established islet graft from male or control female $\mathrm{Rag}^{-1-}$ donors and monitored subsequent graft rejection and the percentage of cells that were Marilyn over time post immune reconstitution (Figure 2C). We found that reconstitution with a mixture of Marilyn and WT HSC (1:4 Marilyn to WT) led to a small but significant fraction $(<30 \% ; 5$ of 17$)$ of recipients rejecting the transplant. This rejection appeared to be associated with the appearance in the periphery of a high ratio of Marilyn to WT $\mathrm{T}$ cells and earlier export of Marilyn T cells into the periphery compared to WT T cells (data not shown). Nevertheless, the vast majority of recipients tolerated the peripheral male islet transplant. In these male islet graft recipients, we compared the frequency of Marilyn T cells (CD45.2 $2^{+}, \mathrm{CD} 45.1^{-}, \mathrm{CD} 4^{+} \mathrm{V} \beta 6^{+}$) to recipients of a control female islet graft. The data in Figure 2D show that the male islet transplant, given 3-4 months prior to a 1:4 (Marilyn:WT) mixture of HSC, causes a slow reduction in frequency of neo-self antigen-specific Marilyn T cells. The mice with male but not female islets were tolerant to the male antigen, as they accepted a male skin graft given 4-6 months post HSC (Figure 2E). Thus, peripheral CD4 tolerance was associated with a decreased frequency of neo-self antigen-specific $\mathrm{T}$ cells over time, with newly generated $\mathrm{T}$ cells having a higher frequency of $\mathrm{CD} 4 \mathrm{~T}$ cells specific to the neo-self antigen.

\section{Host MHC Class II but Not Fas Is Required for Disease upon Transfer of PD-1 $1^{-/}$HSC}

We previously showed that adult Rag $1^{-/-} \mathrm{K}^{\mathrm{b}-/-} \mathrm{D}^{\mathrm{b}-/-}$ mice were fully permissive for the development of autoimmune disease following transfer of PD-1 ${ }^{-/-}$HSC (24); importantly, no perturbations in the time to disease onset or severity were reported compared to $\mathrm{Rag}^{-/-}$hosts, as would be reasonably expected if the disease were CD8 $\mathrm{T}$ cell independent. To delineate the importance of CD4 T cells in this disease model, we generated $\mathrm{Rag}^{-/}$and MHC Class II transactivator-deficient $\left(\mathrm{CiiTA}^{-1-}\right)$ mice, which are largely deficient in MHC-II expression (37). We transferred PD- $1^{-/}$HSC to $\mathrm{Rag}^{-/-}$or $\mathrm{Rag}^{-1-} \times \mathrm{CiiTA}^{-/-}$hosts and monitored the mice for signs of disease. In addition, we examined potential effector mechanisms of disease. Two canonical pathways of T cell killing, namely the FasL-Fas and perforin-dependent pathways, have been described (38). In order to begin to elucidate which, if any, of these pathways are involved in mediating autoimmunity in the PD-1 $1^{-/-}$HSC model, we generated a double mutant Fas ${ }^{\mathrm{pr}} \times \mathrm{Rag}^{-/-}$mouse, which lacks functional Fas expression (39). While $\mathrm{Rag}^{-/-}$mice developed systemic autoimmune disease around day 44 after transfer, $\mathrm{Rag}^{-/-} \times \mathrm{CiiTA}^{-/-}$were completely spared (Figure 3A). Similarly, the pronounced weight loss encountered in the $\mathrm{Rag}^{-/-}$recipient group was not seen in the $\mathrm{Rag}^{-1-} \times \mathrm{CiiTA}^{-1-}$ recipients and indeed the latter group actually gained weight for much of the experiment (Figure 3B) despite CD8 $\mathrm{T}$ cell and $\mathrm{B}$ cell development by day 46 post-transfer (Figure 3C). These data indicate that MHC-II expression in the host is required for disease after $\mathrm{PD}-1^{-/-}$HSC transfer, suggesting disease is dependent on CD4 T cells. Transfer of 

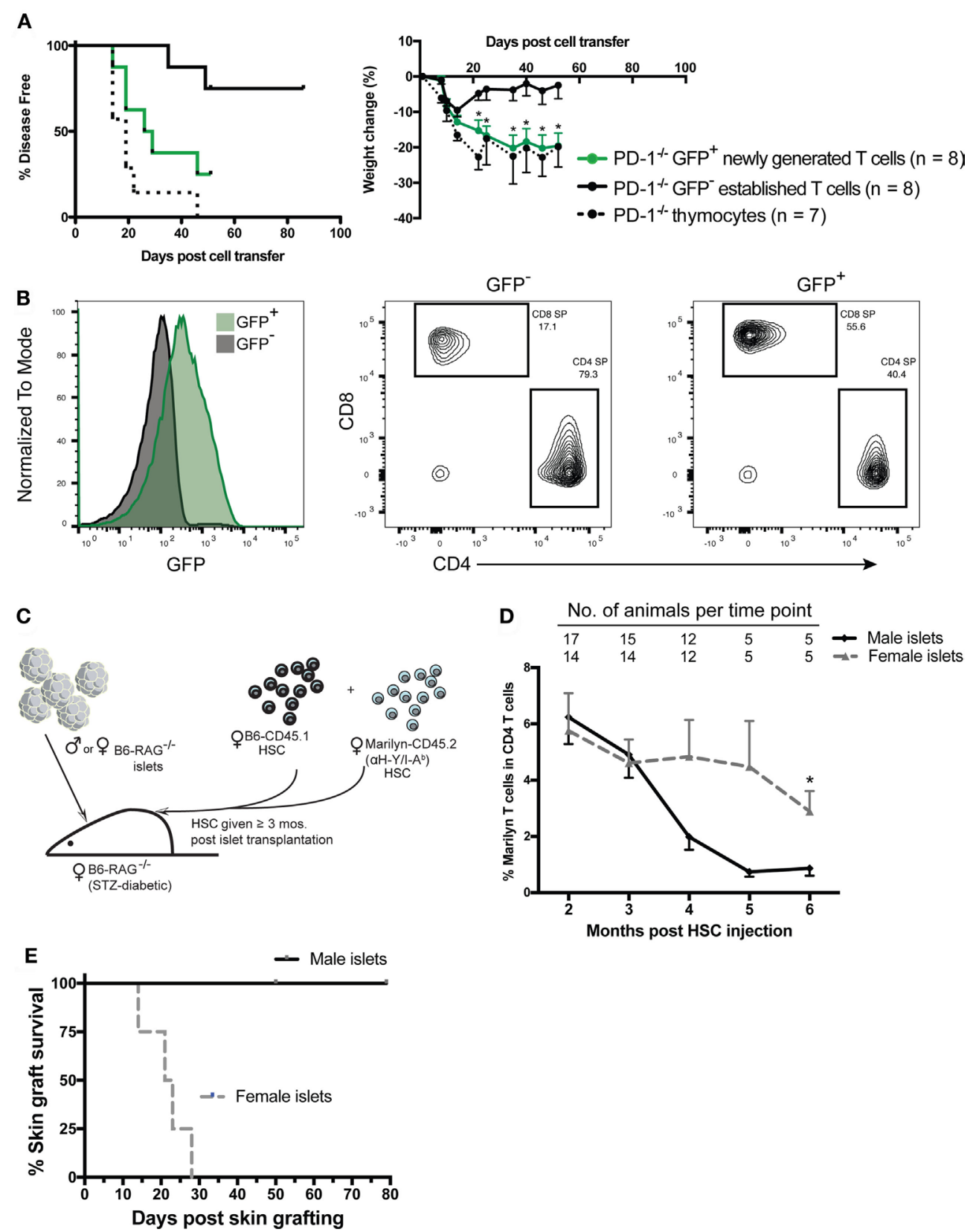

FIGURE 2 | Peripheral PD-1//- newly generated T cells preferentially drive autoimmunity in lymphopenic recipients. CD4 and CD8 single positive (SP), GFP+, and GFP- cells were sorted from 6-week-old Rag2pGFP $\times$ PD-1 $1^{-1}$ splenocytes. $1 \times 10^{6}$ sorted CD4 and CD8 SP GFP+ or GFP- cells, or unfractionated thymocytes containing an equivalent number of CD4 and CD8 SP cells $\left(\sim 8-9 \times 10^{6}\right)$ were injected into NK depleted adult Rag ${ }^{-/ /}$recipients and mice were monitored for disease symptoms. (A) Left panel: disease incidence in recipients of thymocytes, GFP+ newly generated T cells or GFP- established T cells. Survival curve comparison demonstrated a significant difference between the three groups with $p=0.003$; PD-1/- GFP+ newly generated cell recipient vs. established cell recipient curves $p=0.02 ; \mathrm{PD}^{-1^{-/-}}$thymocyte recipient vs. PD-1/- GFP+ newly generated cell recipient curves, $p=$ NS. Data are combined from two independent experiments, starting $n$ values are indicated in the legend. Right panel: weight changes in recipients of indicated cells from two independent experiments \pm SEM. Weight observations for which similar time points were available between experiments ( \pm 2 days) were combined and used for this analysis. ${ }^{*} P<0.05$, GFP ${ }^{n}$ newly generated T cells vs. GFP- established T cells, one-way ANOVA with Tukey's multiple comparison test. (B) Representative GFP expression (left panel) and CD4 and CD8 SP proportions (right 2 panels) in purified cell populations used in (A). (C) Diagram of experimental approach using an established minor mismatched transplant as a model peripheral neo-self antigen and anti-donor (HY) TCR transgenic (Tg) Marilyn T cells to track the frequency of CD4 T cells specific to the "neo-self" antigen over time. Male (or control female) islet transplants were allowed to heal $\geq 3$ months into streptozotocin (STZ)-induced diabetic female Rag ${ }^{-/-}$recipients prior to immune reconstitution via transfer of female hematopoietic stem cells (HSC) from CD45 congenic wild-type (B6-CD45.1) and monoclonal TCR Tg mice. (D) Frequency of Marilyn T cells $\left(C D 4^{+} \mathrm{CD} 45.2^{+} \mathrm{CD} 45.1^{-} \mathrm{V} \beta 6^{+}\right)$within total $\mathrm{CD} 4 \mathrm{~T}$ cells in the peripheral blood of recipients with male vs. female islets that maintained normoglycemia is shown (mean, SEM, and $n$ for each time point is shown). ${ }^{*} p<0.05$, Student's $t$-test. (E) Six months post fetal liver cell injection, male skin grafts were transplanted to normoglycemic Rag $^{-/-}$recipients that had either a male $(n=5)$ or female $(n=4)$ islet transplant and grafts were monitored for rejection. Survival curves are significantly different with $p=0.018$, Mantel-Cox test. 

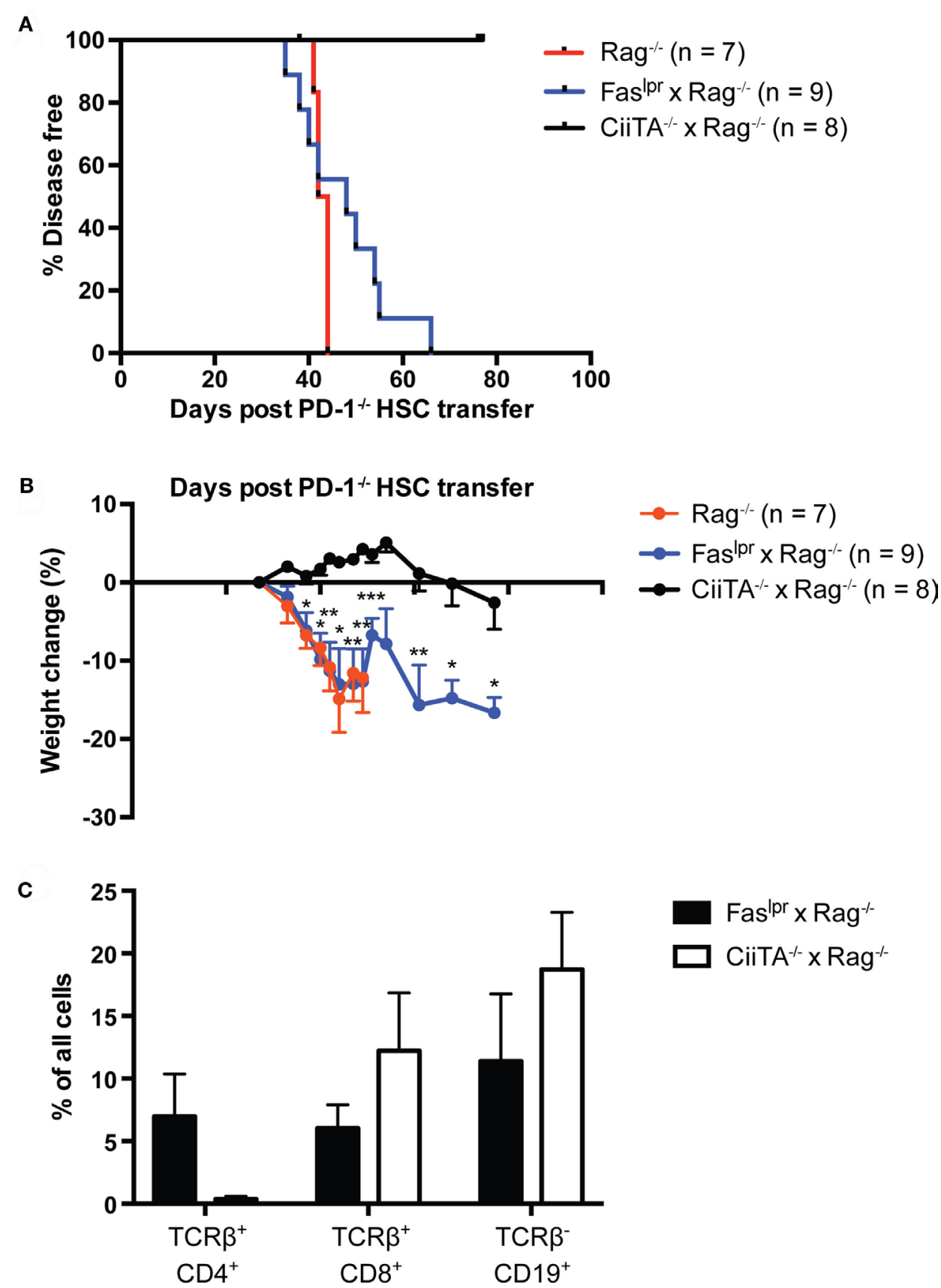

FIGURE 3 | Systemic autoimmunity in lymphopenic PD-1 $1^{-/-}$hematopoietic stem cells (HSC) recipients requires host MHC Class II but not Fas. PD-1 ${ }^{-/-}$HSC were transferred to $\mathrm{Rag}^{-/-}$, Fas ${ }^{\mathrm{lpr}} \times \mathrm{Rag}^{-/-}$, or $\mathrm{CiTA}^{-/-} \times \mathrm{Rag}^{-/-}$recipients and mice were monitored for disease symptoms. (A) Kaplan-Meier survival curve analysis of disease incidence among HSC recipients - groups are significantly different with $p=0.0002$. Data are combined from two independent experiments, with starting numbers per group indicated in the legend. (B) Weight changes in recipients relative to day 27 post-transfer, combined from two independent experiments, \pm SEM. Weight observations for which similar time points were available between experiments ( \pm 2 days) were combined. For each timepoint, only data from groups with $n>2$ are presented. ${ }^{*} p<0.05,{ }^{* *} p<0.01,{ }^{* \star *} p<0.001$, Fas ${ }^{\text {lpr }} \times$ Rag $^{-/-}$vs. CiiTA ${ }^{-/-} \times$Rag $^{-/-}$, one-Way ANOVA with Tukey or Kruskal-Wallis with Dunn's multiple comparison test (days 27-49) or Student's $t$-test (day $>51$ ). (C) \% of all peripheral blood cells that were CD4+ or CD8+ T cells or CD19+ B cells in Fas ${ }^{\text {lpr }} \times$ Rag $^{-/}$ and $\mathrm{CiTA}^{-/-} \times \mathrm{Rag}^{-/-}$recipients from one experiment in (A,B) above, measured at day 46 post-HSC transfer.

PD- $1^{-1-}$ HSC to Fas ${ }^{\mathrm{lpr}} \times \mathrm{Rag}^{-/-}$double mutants revealed that host Fas expression was completely dispensable for the generation of autoimmunity in this model (Figures 3A,B). No statistically significant difference in the survival curves of the $\mathrm{Rag}^{-/-}$and
Fas $^{\text {lpr }} \times \mathrm{Rag}^{-/-}$recipient groups was detected. Similarly, weight loss in $\mathrm{Fas}^{\mathrm{lpr}} \times \mathrm{Rag}^{-/-}$hosts was indistinguishable from that seen in the $\mathrm{Rag}^{-/-}$hosts (Figure 3B). Thus, host Fas expression is not required for disease post $\mathrm{PD}-1^{-/-} \mathrm{HSC}$ transfer. 


\section{Perforin Expression in the Lymphoid Compartment Is Not Required for LIP-Driven Autoimmunity after Transfer of PD-1 ${ }^{-1-}$ Thymocytes}

Next, we examined whether perforin expression in lymphocytes was required for disease following transfer of PD-1 $1^{-/-}$thymocytes to a lymphopenic host. We generated perforin knockout $\left(\mathrm{Prf1}^{-/-}\right)$ and PD-1 ${ }^{-l-}$ mice. The double knockout animals we were able to generate were the F1 progeny of heterozygous crosses and never successfully bred in our facility as homozygous double knockouts (unpublished observations). We transferred thymocytes from the $\mathrm{Prf1}^{-/-}$x PD-1 ${ }^{-/-}$or PD-1 ${ }^{-/-}$mice to $\mathrm{Rag}^{-/-}$recipients and monitored the animals for disease and weight loss. Prf1 $1^{-1-} \times \mathrm{PD}_{-1}^{-1-}$ thymocyte recipients all developed autoimmune disease between days 13 and 21 post-transfer, while the $\mathrm{PD}-1^{-/}$thymocyte recipients had a relatively slightly delayed course of disease (Figure 4A, $p=0.01$ ). Furthermore, weight loss (Figure 4B) was significantly greater in the $\mathrm{Prfl}^{-/-} \times \mathrm{PD}^{-1^{-/}}$thymocyte recipients, and in general the severity of symptoms, particularly diarrhea, appeared greater in this group compared to PD-1 $1^{-/-}$thymocyte recipients. In addition to these findings, we also performed two experiments to question whether $\mathrm{Prf1}^{-1-}$ was required for disease in the HSC transfer model. In the first experiment, $\mathrm{Prf1}^{-/-} \times \mathrm{PD}^{-1^{-/-}} \mathrm{T}$ cell depleted bone marrow cells were transferred to $\mathrm{Rag}^{-/-}$hosts. In the second, Prf1 ${ }^{-1-}$ HSC were transferred to $\mathrm{Rag}^{-/-}$hosts treated intraperitoneally with $200 \mu \mathrm{g} /$ mouse monoclonal blocking antiPD-1 antibody (clone J43) every 2 days from day 25 until termination. In both of these experiments, recipients developed autoimmunity (data not shown) further supporting the notion that perforin expression in $\mathrm{T}$ cells is not required for disease in this model.

Because of the potential for functional redundancy between the Fas-FasL and perforin-dependent killing pathways, we also tested whether adoptive transfer of cells from diseased $\mathrm{Rag}^{-1-}$ recipients of $\mathrm{Prf1}^{-/-} \mathrm{PD}-1^{-/-}$thymocytes to Fas ${ }^{\mathrm{lpr}} \times \mathrm{Rag}^{-/-}$hosts would result in the development of autoimmunity. Indeed, splenocytes + lymph node cells from the diseased Prf1 $1^{-l-} \mathrm{PD}-1^{-/}$thymocyte recipients generated robust development of autoimmunity when transferred either to $\mathrm{Rag}^{-/-}$or Fas ${ }^{\mathrm{lpr}} \times \mathrm{Rag}^{-/-}$recipients (disease onset: day 18, $22,>22$ vs. $13,18 \times 3,22$, respectively; $p=$ NS). Although both recipient groups lost weight, by day 22 post-adoptive transfer the Fas $^{\mathrm{lpr}} \times \mathrm{Rag}^{-/-}$hosts had lost significantly more weight than the $\mathrm{Rag}^{-/-}$recipients (25 vs. 15\%, Figure 4C), suggesting that Fas in the host may actually play an immunoregulatory role. Taken together, these data show that neither perforin expression in $\mathrm{T}$ cells nor Fas expression in the host are required for LIP- and newly generated $\mathrm{T}$ cell-driven autoimmunity in the context of PD-1 deficiency.

\section{DISCUSSION}

Mechanisms of T cell homeostasis function to maintain a diverse repertoire of sufficient size for effective immune surveillance of the host. Reconstitution of the T lymphocyte compartment of a lymphopenic host by HSC transplant or transfer of T cells results in LIP as the cells expand to fill the available niche defined by
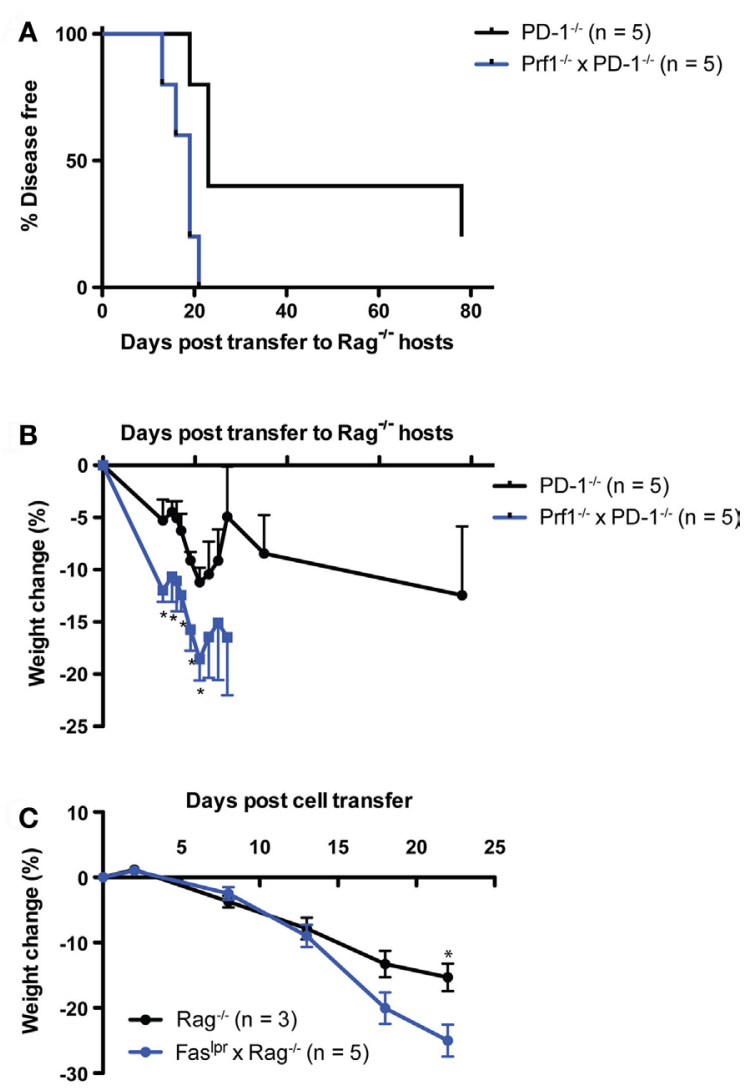

FIGURE 4 | Systemic autoimmunity after PD-1 ${ }^{-/-}$thymocyte transfer to lymphopenic recipients is independent of both perforin and Fas-mediated killing. $10 \times 10^{6}$ Thymocytes from PD-1 ${ }^{-/-}$or Perforin ${ }^{-/} \times \mathrm{PD}-1^{-/-}$

$\left(\mathrm{Prf}^{-/-} \times \mathrm{PD}-1^{-/-}\right)$animals were transferred i.v. to NK depleted adult $\mathrm{Rag}^{-/-}$recipients and mice were monitored for disease symptoms.

(A) Kaplan-Meier survival curve analysis of disease incidence among individual recipients of the indicated thymocytes. Survival curve comparison demonstrated a significant difference between the two groups with $p=0.01$. (B) Weight change among the recipients in (A), \pm SEM. Data are from one experiment, starting $n$ values are indicated in the legend. (C) Splenocytes and inguinal lymph node cells were harvested from three diseased $\mathrm{Prf1}^{-/-} \times \mathrm{PD}-1^{-/-}$thymocyte recipients from the experiment depicted in (A) at day 28 post-transfer, and $20 \times 10^{6}$ cells were transferred i.v. into NK depleted, adult Rag ${ }^{-/}$or Fas ${ }^{\mathrm{lpr}} \times \mathrm{Rag}^{-/}$recipients. One Fas ${ }^{\mathrm{IPr}} \times \mathrm{Rag}^{-/-}$ recipient received $10 \times 10^{6}$ cells. Weight change among cell recipients, \pm SEM. ${ }^{*} p<0.05$, Student's $t$-test. Data are from one experiment with starting $n$ values in the legend.

available peptide-MHC (pMHC) and cytokine "resources." The relative abundance of resources in a host with respect to the numbers of competitors for those resources can be considered as a way to define the "severity" of lymphopenia in that host or its "LIP-potential" (40). Importantly, LIP is strongly associated with the promotion of autoimmune or inflammatory disease $(5,13,17,24,40-49)$. Such promotion of autoimmunity may result from potentiation of TCR signaling by high concentrations of homeostatic cytokines like IL-7 and IL-15 $(50,51)$ and/ or unimpeded access to self-pMHC due to decreased competition from other Tcon or Treg. Thus, perturbations which would be expected to increase the LIP potential of a host, such as 
decreased Treg, increased homeostatic cytokines, or decreases in co-inhibitory signals would be expected to increase the potential for such autoimmunity, and vice versa. Newly generated $\mathrm{T}$ cells during LIP appear particularly predisposed to the generation of autoimmunity when PD-1 mediated co-inhibitory signals are compromised (24). Newly generated T cells have not been subjected to peripheral tolerance mechanisms and thus may contain an increased proportion of strongly self-reactive cells compared to established $\mathrm{T}$ cells that arose in a host with low LIP potential upon initial seeding of its peripheral $\mathrm{T}$ cell compartment (i.e., during the neonatal period) and were tolerized. Indeed, in the current studies, we showed that a high frequency of CD4 T cells specific to a peripheral neo-self antigen can persist for an extended period in a lymphoreplete adult host, declining slowly with time without overt immune-mediated pathology (i.e., lack of rejection of the neoantigen expressing graft; Figures 2C-E). In addition, we have recently shown that PD-1 contributes to control of tonic pMHC signaling, which may tune signaling thresholds to establish a general $\mathrm{T}$ cell homeostasis needed for peripheral tolerance (52). Altogether our data suggests that PD-1 is more critical for control of newly generated CD4 T cells because of increased self-specific T cells in this population as well as a need to set response thresholds to tonic pMHC signals in all CD4 T cells. Although this view is consistent with recent findings from Jiang and colleagues, in which they showed PD-1 was important in reducing the number of high-affinity self-specific CD4 T cells (53), their conclusion differs substantially from our own. While they concluded that PD-1 is needed to maintain tolerance, both their data and ours are instead consistent with the view that PD-1 is needed to establish tolerance, with $\mathrm{PD}-1$ playing relatively little or no role in the maintenance of tolerance once it is established. On the other hand, much of the published literature describing newly generated $\mathrm{T}$ cells/RTE suggests that they have functional properties geared toward promotion of tolerance (26). However, we found that newly generated $\mathrm{PD}-1^{-1-} \mathrm{T}$ cells isolated from the periphery of adult animals were indeed capable of generating autoimmune disease (particularly cachexia, kyphosis, and diarrhea) similar to $\mathrm{PD}-1^{-/-}$thymocytes, and much more efficiently than established $\mathrm{T}$ cells which contained approximately $1.3 \%$ contaminating $\mathrm{GFP}^{+}$cells (Figure 2A). These data indicate that steady state newly generated $\mathrm{T}$ cells have a dangerous autoimmune potential even when their initial export from the thymus is into a lymphoreplete environment.

Tolerance first becomes established in mice during the neonatal period. Compared to adult $\mathrm{Rag}^{-/-}$mice, we consider that prior to/during initial seeding of the lymphoid compartment neonatal mice would, by virtue of anatomic size (small lymph nodes, reduced overall resources) and competition by specialized populations of innate lymphoid cells for IL-7 (54) have significantly lower LIP potential. This is supported by our finding that neonatal $\mathrm{Rag}^{-/-}$hosts rarely developed severe autoimmunity after reconstitution with $\mathrm{PD}-1^{-/-}$HSC (24). A lymphoreplete adult WT host on the other hand would be considered to have lower LIP potential than either an adult $\mathrm{Rag}^{-/-}$or a WT neonate (i.e., the ranking of LIP potential would be adult $\mathrm{Rag}^{-/-}>$neonatal WT $>$ adult WT) (40). We hypothesize that the mild but significant LIP potential in neonates creates a situation in which establishment of tolerance in the nascent $\mathrm{T}$ cell population by PD-1 is important, and the absence of PD-1-mediated control of neonatal LIP may set the stage for the lupus-like autoimmunity that manifests later in life in PD-1 $1^{-1-}$ animals.

Although PD-1 is critical for tolerance in newly generated $\mathrm{T}$ cells, and PD-1 was expressed on neonatal T cells undergoing LIP, we did not, in the steady state, detect PD-1 expression above background on the peripheral newly generated $\mathrm{T}$ cell population of adult Rag2pGFP mice and only low expression in thymic $\mathrm{GFP}^{+} \mathrm{T}$ cells (Figure 1). In contrast, both the peripheral CD4 SP and thymic CD4 and CD8 SP established $\left(\mathrm{GFP}^{-}\right) \mathrm{T}$ cell population contained sizeable populations that robustly expressed PD-1. Previous data from our lab assessing PD-1 expression in steady state RTE (i.e., in WT lymphoreplete mice) used CD24 as the marker to define RTE and the data suggested RTE have higher PD-1 (24). However, based on our current data with the Rag2pGFP mouse and the fact that only a small fraction of newly generated T cells expressed CD24 and established $\mathrm{T}$ cells can also express CD24, we conclude that steady-state adult newly generated $\mathrm{T}$ cells do not have increased PD-1. Together with our finding that PD-1 can regulate LIP and the response to tonic pMHC signals $(25,52)$, these observations suggest that PD-1 is upregulated during LIP as a negative feedback mechanism. Finally, it is worth noting that because a significant portion (10-15\%) of thymic $\mathrm{T}$ cells are established cells based on lack of GFP expression, consistent with the previously described ability of peripheral $\mathrm{T}$ cells to recirculate back to the thymus (55), the use of the term "recent thymic emigrants" to describe $\mathrm{GFP}^{+}$cells in the Rag2pGFP Tg model as is common in the literature is somewhat imprecise as presumably some cells emerging from the thymus in an adult are also $\mathrm{GFP}^{-}$. Therefore, although all peripheral $\mathrm{GFP}^{+}$cells are RTE, all RTE are not necessarily GFP ${ }^{+}$.

One potential explanation for our finding that purified peripheral newly generated $\mathrm{T}$ cells efficiently caused disease upon transfer to lymphopenic hosts while established cells did not is that the relative proportions of CD4 and CD8 T cells differed significantly between these populations. Based on the present data including the lack of disease in $\mathrm{CiiTA}^{-1-}$ hosts despite generation of CD8 T cells and B cells (Figure 3C) and our previous findings that MHC Class I-deficient lymphopenic hosts were fully disease permissive, we conclude that CD4 T cells in this setting are the key effectors of autoimmune pathology. Given that the purified established $\mathrm{T}$ cell population contained a greater frequency of CD4 vs. CD8 T cells, their inability to drive disease (and conversely the ability of $\mathrm{GFP}^{+} \mathrm{PD}-1^{-/-}$newly generated cells to do so) cannot be explained by insufficient numbers of CD4 T cells.

While CD4 T cells are most commonly considered as "helpers" of the immune response, numerous studies have suggested that they can in some circumstances acquire cytolytic effector function via upregulation of killing mechanisms typically associated with CD8 cytotoxic T lymphocytes such as the perforin and Fas-ligand (FasL) pathways (56). Our finding that neither Fas ${ }^{\mathrm{lpr}} \times \mathrm{Rag}^{-/-}$recipients of $\mathrm{PD}-1^{-/-} \mathrm{HSC}$, nor recipients of $\mathrm{Prfl}^{-/-} \times \mathrm{PD}^{-1} 1^{-/-}$thymocytes were spared from disease 
(Figures 3 and 4A,B) suggests that both of these canonical T cell effector pathways are dispensable for LIP-driven autoimmunity in the setting of PD-1 deficiency. Furthermore, our finding that disease in $\mathrm{Prf1}^{-/-} \times \mathrm{PD}^{-1^{-/}}$thymocyte recipients was exacerbated compared to PD-1 ${ }^{-/-}$thymocyte recipients (Figures 4A,B) suggests that perforin-dependent effector pathways may actually play an immunoregulatory role during LIP. This is perhaps not surprising given that perforin has been reported to be important for contraction of the CD8 population following infection $(57,58)$, and as a mediator of suppression by $\operatorname{Tr} 1$ cells (59). Similarly, weight loss of increased severity in the Fas ${ }^{\mathrm{lpr}} \times \mathrm{Rag}^{-/-}$ compared to $\mathrm{Rag}^{-/-}$recipients of adoptively transferred $\mathrm{Prf1}^{-/-} \mathrm{PD}-1^{-/-}$cells (Figure 4C) suggested that Fas may also play an immunoregulatory role during LIP. This might also be anticipated given the lymphoproliferative disease characteristic of the Fas and Fas-ligand-deficient lpr and gld mice (60) which is partially attributable to defects in Fas-mediated killing of antigen-presenting cells (61). The latter experiment also ruled out functional redundancy between Fas-FasL and perforindependent killing pathways. We did consider the possibility that Granzyme B produced by $\mathrm{T}$ cells activated during LIP might act independently of perforin, for example through the mannose-6-phosphate receptor (62). However, examination of Granzyme B expression in WT vs. PD- $1^{-1-}$ HSC recipients at the peak of disease (day 45) demonstrated no significant difference in splenic CD4 or CD8 T cell populations although a small trend toward increased expression in $\mathrm{PD}-1^{-/}$HSC recipient CD8 T cells was noted (Figure S2 in Supplementary Material).

The broad upregulation of a number of pro-inflammatory cytokines in PD- $1^{-/-}$HSC recipients (IFN- $\gamma$, IL-13, TNF- $\alpha$, IP-10, MIG, MCP-1, VEGF) (24) along with the lack of requirement for either perforin- or Fas-dependent killing pathways for autoimmunity in this model suggest that the immune pathology seen is primarily a CD4 T cell and "cytokine-storm" dependent phenomenon. Several similarities exist between the LIP-driven autoimmunity described herein and certain clinical syndromes, such as immune reconstitution inflammatory syndrome (IRIS) in HIV patients experiencing a rebound of the CD4 $\mathrm{T}$ cell compartment after treatment with antiviral drugs $(44,63)$ or in chronic GVHD post-allogeneic bone marrow transplantation (64). Notably a mouse model of IRIS was recently described in which transfer of purified CD4 T cells to Cryoptococcus-infected lymphopenic mice yields weight loss and systemic inflammatory disease associated with cytokine dysregulation (45). In addition, the striking increases in the chemokines IP-10 and MIG described previously in our model (24) are also observed in clinical chronic GVHD (65). Indeed, the term "cytokine-storm" was originally used to describe the syndrome of cytokine dysregulation (particularly IL-6, IL-1, and TNF- $\alpha$ ) which is associated with and greatly contributes to GVHD pathology $(66,67)$. One could make the argument that our model of LIP-driven autoimmunity after transfer of $\mathrm{PD}-1^{-/-}$newly generated $\mathrm{T}$ cells to a lymphopenic host might actually be viewed as a model of syngeneic GVHD, similar to the autoimmunity that occurs when cyclosporine A (CsA) is discontinued post bone marrow transplantation. However, broad-spectrum antibiotics prevented CsA-induced syngeneic GVHD (68) but did not prevent disease in our model (25). Instead, the stimulus for PD-1-deficient RTE appears to involve autoantigens, potentially including the low-affinity interactions with self-peptide MHC that otherwise generate only tonic survival signals (40). Thus, beyond the insights it offers into the role of co-inhibitory molecules in establishing tolerance, further characterization of this model may lead to translatable insights to treat cytokine-driven systemic autoimmunity and inflammatory disease including after therapies involving immune reconstitution.

\section{ETHICS STATEMENT}

This study was carried out in accordance with the recommendations of the Canadian Council on Animal Care. The protocol was approved by the University of Alberta Health Sciences Animal Care and Use Committee.

\section{AUTHOR CONTRIBUTIONS}

KE designed, performed research and data analysis, and wrote and critically edited the manuscript. GT, YH, and JL designed and performed research and data analysis and critically edited the manuscript. LB provided reagents and critically edited the manuscript. CA designed research, performed data analysis, and critically edited the manuscript.

\section{ACKNOWLEDGMENTS}

The authors would like to thank Perveen Anwar and HSLAS staff for assistance with animal care and Deb Dixon for islet transplantation. This manuscript includes material previously included in the doctoral dissertation of KE (69).

\section{FUNDING}

This research has been supported by operating funds to CA from the Canadian Institutes of Health Research (PS148588, FRN79521), the Muttart Diabetes Research and Training Centre, the Women and Children's Health Research Institute (WCHRI) through the generous support of The Stollery Children's Hospital Foundation and by doctoral studentships from the Alberta Diabetes Institute and Alberta Innovates Health Solutions (AIHS) to $\mathrm{KE}$ and a senior scholar award from AIHS to CA.

\section{SUPPLEMENTARY MATERIAL}

The Supplementary Material for this article can be found online at http://www.frontiersin.org/articles/10.3389/fimmu.2018.00012/ full\#supplementary-material. 


\section{REFERENCES}

1. Hogquist KA, Jameson SC. The self-obsession of T cells: how TCR signaling thresholds affect fate "decisions" and effector function. Nat Immunol (2014) 15:815-23. doi:10.1038/ni.2938

2. Wekerle H, Bradl M, Linington C, Kääb G, Kojima K. The shaping of the brain-specific T lymphocyte repertoire in the thymus. Immunol Rev (1996) 149:231-43. doi:10.1111/j.1600-065X.1996.tb00907.x

3. Min B, McHugh R, Sempowski GD, Mackall C, Foucras G, Paul WE. Neonates support lymphopenia-induced proliferation. Immunity (2003) 18:131-40. doi:10.1016/S1074-7613(02)00508-3

4. Takada K, Jameson SC. Naive T cell homeostasis: from awareness of space to a sense of place. Nat Rev Immunol (2009) 9:823-32. doi:10.1038/nri2657

5. Almeida ARM, Legrand N, Papiernik M, Freitas AA. Homeostasis of peripheral CD4+ T cells: IL-2R alpha and IL-2 shape a population of regulatory cells that controls CD4+ T cell numbers. J Immunol (2002) 169:4850-60. doi:10.4049/jimmunol.169.9.4850

6. Annacker O, Pimenta-Araujo R, Burlen-Defranoux O, Barbosa TC, Cumano A, Bandeira A. CD25+ CD4+ T cells regulate the expansion of peripheral CD4 T cells through the production of IL-10. J Immunol (2001) 166:3008-18. doi:10.4049/jimmunol.166.5.3008

7. Hagen KA, Moses CT, Drasler EF, Podetz-Pedersen KM, Jameson SC, Khoruts A. A role for CD28 in lymphopenia-induced proliferation of CD4 T cells. J Immunol (2004) 173:3909-15. doi:10.4049/jimmunol.173.6.3909

8. Shen S, Ding Y, Tadokoro CE, Olivares-Villagómez D, Camps-Ramírez M, Curotto de Lafaille MA, et al. Control of homeostatic proliferation by regulatory T cells. J Clin Invest (2005) 115:3517-26. doi:10.1172/JCI25463

9. Bourgeois C, Stockinger B. CD25+CD4+ regulatory T cells and memory $\mathrm{T}$ cells prevent lymphopenia-induced proliferation of naive $\mathrm{T}$ cells in transient states of lymphopenia. J Immunol (2006) 177:4558-66. doi:10.4049/jimmunol. 177.7.4558

10. Winstead CJ, Fraser JM, Khoruts A. Regulatory CD4+CD25+Foxp3+ $\mathrm{T}$ cells selectively inhibit the spontaneous form of lymphopenia-induced proliferation of naive T cells. J Immunol (2008) 180:7305-17. doi:10.4049/ jimmunol.180.11.7305

11. Sojka DK, Hughson A, Fowell DJ. CTLA-4 is required by CD4+CD25+ Treg to controlCD4+T-celllymphopenia-induced proliferation. EurJ Immunol(2009) 39:1544-51. doi:10.1002/eji.200838603

12. Winstead CJ, Reilly CS, Moon JJ, Jenkins MK, Hamilton SE, Jameson SC, et al. CD4+CD25+Foxp3+ regulatory T cells optimize diversity of the conventional $\mathrm{T}$ cell repertoire during reconstitution from lymphopenia. J Immunol (2010) 184:4749-60. doi:10.4049/jimmunol.0904076

13. Bolton HA, Zhu E, Terry AM, Guy TV, Koh W-P, Tan S-Y, et al. Selective Treg reconstitution during lymphopenia normalizes DC costimulation and prevents graft-versus-host disease. J Clin Invest (2015) 125:3627-41. doi:10.1172/ JCI76031

14. Gudmundsdottir H, Turka LA. A closer look at homeostatic proliferation of CD4+ T cells: costimulatory requirements and role in memory formation. J Immunol (2001) 167:3699-707. doi:10.4049/jimmunol.167.7.3699

15. Krieg C, Boyman O, Fu Y-X, Kaye J. B and T lymphocyte attenuator regulates CD8+ T cell-intrinsic homeostasis and memory cell generation. Nat Immunol (2007) 8:162-71. doi:10.1038/ni1418

16. Workman CJ, Vignali DAA. Negative regulation of $\mathrm{T}$ cell homeostasis by lymphocyte activation gene-3 (CD223). J Immunol (2005) 174:688-95. doi:10.4049/jimmunol.174.2.688

17. Zhang $\mathrm{N}$, Bevan MJ. TGF- $\beta$ signaling to $\mathrm{T}$ cells inhibits autoimmunity during lymphopenia-driven proliferation. Nat Immunol (2012) 13:667-73. doi:10.1038/ni.2319

18. Sledzińska A, Hemmers S, Mair F, Gorka O, Ruland J, Fairbairn L, et al. TGF- $\beta$ signalling is required for $\mathrm{CD} 4^{+} \mathrm{T}$ cell homeostasis but dispensable for regulatory T cell function. PLoS Biol (2013) 11:e1001674. doi:10.1371/journal. pbio. 1001674

19. Pentcheva-Hoang T, Chen L, Pardoll DM, Allison JP. Programmed death-1 concentration at the immunological synapse is determined by ligand affinity and availability. Proc Natl Acad Sci U S A (2007) 104:17765-70. doi:10.1073/ pnas.0708767104

20. Yokosuka T, Takamatsu M, Kobayashi-Imanishi W, Hashimoto-Tane A, Azuma M, Saito T. Programmed cell death 1 forms negative costimulatory microclusters that directly inhibit $\mathrm{T}$ cell receptor signaling by recruiting phosphatase SHP2. J Exp Med (2012) 209:1201-17. doi:10.1038/nri2326

21. Sheppard K-A, Fitz LJ, Lee JM, Benander C, George JA, Wooters J, et al. PD-1 inhibits T-cell receptor induced phosphorylation of the ZAP70/CD3zeta signalosome and downstream signaling to PKCtheta. FEBS Lett (2004) 574:37-41. doi:10.1016/j.febslet.2004.07.083

22. Hui E, Cheung J, Zhu J, Su X, Taylor MJ, Wallweber HA, et al. T cell costimulatory receptor $\mathrm{CD} 28$ is a primary target for $\mathrm{PD}-1$-mediated inhibition. Science (2017) 355:1428-33. doi:10.1126/science.aaf1292

23. Nishimura H, Nose M, Hiai H, Minato N, Honjo T. Development of lupuslike autoimmune diseases by disruption of the PD-1 gene encoding an ITIM motif-carrying immunoreceptor. Immunity (1999) 11:141-51. doi:10.1016/ S1074-7613(00)80089-8

24. Thangavelu G, Parkman JC, Ewen CL, Uwiera RRE, Baldwin TA, Anderson CC. Programmed death-1 is required for systemic self-tolerance in newly generated $\mathrm{T}$ cells during the establishment of immune homeostasis. J Autoimmun (2011) 36:301-12. doi:10.1016/j.jaut.2011.02.009

25. Ellestad KK, Thangavelu G, Ewen CL, Boon L, Anderson CC. PD-1 is not required for natural or peripherally induced regulatory $\mathrm{T}$ cells: severe autoim munity despite normal production of regulatory T cells. Eur J Immunol (2014) 44:3560-72. doi:10.1002/eji.201444688

26. Fink PJ. The biology of recent thymic emigrants. Annu Rev Immunol (2013) 31:31-50. doi:10.1146/annurev-immunol-032712-100010

27. Yu W, Nagaoka H, Jankovic M, Misulovin Z, Suh H, Rolink A, et al. Continued RAG expression in late stages of B cell development and no apparent reinduction after immunization. Nature (1999) 400:682-7. doi:10.1038/23287

28. Boursalian TE, Golob J, Soper DM, Cooper CJ, Fink PJ. Continued maturation of thymic emigrants in the periphery. Nat Immunol (2004) 5:418-25. doi:10.1038/ni1049

29. Lantz O, Grandjean I, Matzinger P, Di Santo JP. Gamma chain required for naïve CD4+ T cell survival but not for antigen proliferation. Nat Immunol (2000) 1:54-8. doi:10.1038/76917

30. Rivas MN, Hazzan M, Weatherly K, Gaudray F, Salmon I, Braun MY. NK cell regulation of CD4 $\mathrm{T}$ cell-mediated graft-versus-host disease. J Immunol (2010) 184:6790-8. doi:10.4049/jimmunol.0902598

31. Cerboni C, Zingoni A, Cippitelli M, Piccoli M, Frati L, Santoni A. Antigenactivated human $\mathrm{T}$ lymphocytes express cell-surface NKG2D ligands via an ATM/ATR-dependent mechanism and become susceptible to autologous NK-cell lysis. Blood (2007) 110:606-15. doi:10.1182/blood-2006-10-052720

32. Rabinovich BA, Li J, Shannon J, Hurren R, Chalupny J, Cosman D, et al. Activated, but not resting, $\mathrm{T}$ cells can be recognized and killed by syngeneic NK cells. J Immunol (2003) 170:3572-6. doi:10.4049/jimmunol.170.7.3572

33. Chan WFN, Perez-Diez A, Razavy H, Anderson CC. The ability of natural tolerance to be applied to allogeneic tissue: determinants and limits. Biol Direct (2007) 2:10. doi:10.1186/1745-6150-2-10

34. Nanji SA, Hancock WW, Luo B, Schur CD, Pawlick RL, Zhu LF, et al. Costimulation blockade of both inducible costimulator and CD40 ligand induces dominant tolerance to islet allografts and prevents spontaneous autoimmune diabetes in the NOD mouse. Diabetes (2006) 55:27-33. doi:10.2337/ diabetes.55.01.06.db04-1154

35. Bhaumik S, Giffon T, Bolinger D, Kirkman R, Lewis DB, Weaver CT, et al. Retinoic acid hypersensitivity promotes peripheral tolerance in recent thymic emigrants. J Immunol (2013) 190:2603-13. doi:10.4049/jimmunol.1200852

36. Paiva RS, Lino AC, Bergman M-L, Caramalho I, Sousa AE, Zelenay S, et al. Recent thymic emigrants are the preferential precursors of regulatory $\mathrm{T}$ cells differentiated in the periphery. Proc Natl Acad Sci U S A (2013) 110:6494-9. doi:10.1073/pnas.1221955110

37. Chang $\mathrm{CH}$, Guerder S, Hong SC, van Ewijk W, Flavell RA. Mice lacking the MHC class II transactivator (CIITA) show tissue-specific impairment of MHC class II expression. Immunity (1996) 4:167-78. doi:10.1016/S1074-7613 (00)80681-0

38. Lowin B, Hahne M, Mattmann C, Tschopp J. Cytolytic T-cell cytotoxicity is mediated through perforin and Fas lytic pathways. Nature (1994) 370:650-2. doi: $10.1038 / 370650 \mathrm{a} 0$

39. Drappa J, Brot N, Elkon KB. The Fas protein is expressed at high levels on CD4+CD8+ thymocytes and activated mature lymphocytes in normal mice but not in the lupus-prone strain, MRL lpr/lpr. Proc Natl Acad Sci U S A (1993) 90:10340-4. doi:10.1073/pnas.90.21.10340 
40. Ellestad KK, Anderson CC. Two strikes and you're out? The pathogenic interplay of coinhibitor deficiency and lymphopenia-induced proliferation. J Immunol (2017) 198:2534-41. doi:10.4049/jimmunol.1601884

41. Krupica T Jr, Fry TJ, Mackall CL. Autoimmunity during lymphopenia: a twohit model. Clin Immunol (2006) 120:121-8. doi:10.1016/j.clim.2006.04.569

42. Le Campion A, Gagnerault M-C, Auffray C, Bécourt C, Poitrasson-Rivière M, Lallemand E, et al. Lymphopenia-induced spontaneous T-cell proliferation as a cofactor for autoimmune disease development. Blood (2009) 114:1784-93. doi:10.1182/blood-2008-12-192120

43. Calzascia T, Pellegrini M, Lin A, Garza KM, Elford AR, Shahinian A, et al. CD4 T cells, lymphopenia, and IL-7 in a multistep pathway to autoimmunity. Proc Natl Acad Sci U S A (2008) 105:2999-3004. doi:10.1073/pnas.0712135105

44. Lawn SD, Meintjes G. Pathogenesis and prevention of immune reconstitution disease during antiretroviral therapy. Expert Rev Anti Infect Ther (2011) 9: 415-30. doi:10.1586/eri.11.21

45. Eschke M, Piehler D, Schulze B, Richter T, Grahnert A, Protschka M, et al. A novel experimental model of Cryptococcus neoformans-related immune reconstitution inflammatory syndrome (IRIS) provides insights into pathogenesis. Eur J Immunol (2015) 45:3339-50. doi:10.1002/eji.201545689

46. Vignali D, Monti P. Targeting homeostatic T cell proliferation to control beta-cell autoimmunity. Curr Diab Rep (2016) 16:40-8. doi:10.1007/s11892016-0731-9

47. Datta S, Sarvetnick N. Lymphocyte proliferation in immune-mediated diseases. Trends Immunol (2009) 30:430-8. doi:10.1016/j.it.2009.06.002

48. McPherson SW, Heuss ND, Gregerson DS. Lymphopenia-induced proliferation is a potent activator for $\mathrm{CD} 4+\mathrm{T}$ cell-mediated autoimmune disease in the retina. J Immunol (2009) 182:969-79. doi:10.4049/jimmunol.182.2.969

49. McHugh RS, Shevach EM. Cutting edge: depletion of CD4+CD25+ regulatory $\mathrm{T}$ cells is necessary, but not sufficient, for induction of organ-specific autoimmune disease. J Immunol (2002) 168:5979-83. doi:10.4049/jimmunol. 168.12.5979

50. Deshpande P, Cavanagh MM, Le Saux S, Singh K, Weyand CM, Goronzy JJ. IL-7- and IL-15-mediated TCR sensitization enables T cell responses to self-antigens. J Immunol (2013) 190:1416-23. doi:10.4049/jimmunol.1201620

51. Dooms H. Interleukin-7: fuel for the autoimmune attack. J Autoimmun (2013) 45:40-8. doi:10.1016/j.jaut.2013.06.007

52. Ellestad KK, Lin J, Boon L, Anderson CC. PD-1 controls tonic signaling and lymphopenia-induced proliferation of T lymphocytes. Front Immunol (2017) 8:1289. doi:10.3389/fimmu.2017.01289

53. Jiang TT, Martinov T, Xin L, Kinder JM, Spanier JA, Fife BT, et al. Programmed death-1 culls peripheral accumulation of high-affinity autoreactive CD4 T cells to protect against autoimmunity. Cell Rep (2016) 17:1783-94. doi:10.1016/j. celrep.2016.10.042

54. Bank U, Deiser K, Finke D, Hämmerling GJ, Arnold B, Schüler T. Cutting edge: innate lymphoid cells suppress homeostatic $\mathrm{T}$ cell expansion in neonatal mice. J Immunol (2016) 196:3532-6. doi:10.4049/jimmunol.1501643

55. Michie SA, Kirkpatrick EA, Rouse RV. Rare peripheral T cells migrate to and persist in normal mouse thymus. J Exp Med (1988) 168:1929-34. doi:10.1084/ jem.168.5.1929

56. Cheroutre H, Husain MM. CD4 CTL: living up to the challenge. Semin Immunol (2013) 25:273-81. doi:10.1016/j.smim.2013.10.022
57. Kägi D, Odermatt B, Mak TW. Homeostatic regulation of CD8+ T cells by perforin. Eur J Immunol (1999) 29:3262-72. doi:10.1002/(SICI)1521-4141 (199910)29:10<3262::AID-IMMU3262>3.0.CO;2-A

58. Badovinac VP, Tvinnereim AR, Harty JT. Regulation of antigen-specific CD8+ T cell homeostasis by perforin and interferon-gamma. Science (2000) 290:1354-8. doi:10.1126/science.290.5495.1354

59. Pot C, Apetoh L, Kuchroo VK. Type 1 regulatory T cells $(\operatorname{Tr} 1)$ in autoimmunity. Semin Immunol (2011) 23:202-8. doi:10.1016/j.smim.2011.07.005

60. Nagata S, Suda T. Fas and Fas ligand: lpr and gld mutations. Immunol Today (1995) 16:39-43. doi:10.1016/0167-5699(95)80069-7

61. Stranges PB, Watson J, Cooper CJ, Choisy-Rossi C-M, Stonebraker AC, Beighton RA, et al. Elimination of antigen-presenting cells and autoreactive $\mathrm{T}$ cells by Fas contributes to prevention of autoimmunity. Immunity (2007) 26:629-41. doi:10.1016/j.immuni.2007.03.016

62. Motyka B, Korbutt G, Pinkoski MJ, Heibein JA, Caputo A, Hobman M, et al. Mannose 6-phosphate/insulin-like growth factor II receptor is a death receptor for granzyme B during cytotoxic T cell-induced apoptosis. Cell (2000) 103:491-500. doi:10.1016/S0092-8674(00)00140-9

63. Müller M, Wandel S, Colebunders R, Attia S, Furrer H, Egger M. IeDEA Southern and Central Africa. Immune reconstitution inflammatory syndrome in patients starting antiretroviral therapy for HIV infection: a systematic review and meta-analysis. Lancet Infect Dis (2010) 10:251-61. doi:10.1016/ S1473-3099(10)70026-8

64. MacDonald KP, Blazar BR, Hill GR. Cytokine mediators of chronic graftversus-host disease. J Clin Invest (2017) 127:2452-63. doi:10.1172/JCI90593

65. Kariminia A, Holtan SG, Ivison S, Rozmus J, Hebert M-J, Martin PJ, et al. Heterogeneity of chronic graft-versus-host disease biomarkers: association with CXCL10 and CXCR3+ NK cells. Blood (2016) 127:3082-91. doi:10.1182/ blood-2015-09-668251

66. Ferrara JL, Abhyankar S, Gilliland DG. Cytokine storm of graft-versus-host disease: a critical effector role for interleukin-1. Transplant Proc (1993) 25:1216-7.

67. Henden AS, Hill GR. Cytokines in graft-versus-host disease. J Immunol (2015) 194:4604-12. doi:10.4049/jimmunol.1500117

68. Brandon JA, Jennings CD, Kaplan AM, Bryson JS. Murine syngeneic graftversus-host disease is responsive to broad-spectrum antibiotic therapy. J Immunol (2011) 186:3726-34. doi:10.4049/jimmunol.1003343

69. Ellestad KK. Mechanisms underlying lymphopenia-driven autoimmunity in the setting of co-inhibitory molecule deficiency [dissertation]. Edmonton, $\mathrm{AB}$ : University of Alberta (2016).

Conflict of Interest Statement: The authors declare that the research was conducted in the absence of any commercial or financial relationships that could be construed as a potential conflict of interest.

Copyright $\odot 2018$ Ellestad, Thangavelu, Haile, Lin, Boon and Anderson. This is an open-access article distributed under the terms of the Creative Commons Attribution License (CC BY). The use, distribution or reproduction in other forums is permitted, provided the original author(s) or licensor are credited and that the original publication in this journal is cited, in accordance with accepted academic practice. No use, distribution or reproduction is permitted which does not comply with these terms. 